\title{
An Improved Mutation Series Entropy-based Algorithm for Evaluation of Innovation Ability of Enterprises
}

\author{
Chen Gong ${ }^{\mathrm{a}, *}$, Kexin $\mathrm{Bi}^{\mathrm{a}}$, and Zaoli Yang ${ }^{\mathrm{b}}$ \\ ${ }^{a}$ School of Economics and Management, Harbin Engineering University, Harbin, 150001, China \\ ${ }^{b}$ School of Economics and Management, Beijing University of Technology, Beijing, 100124, China
}

\begin{abstract}
Based on the evaluation model of the entropy evaluation method and mutation series method, this paper evaluates the independent innovation ability of high-tech industry areas of China during the period of 2005 to 2011. It also emphatically analyzes the independent innovation of an underdeveloped area of China, the Heilongjiang Province. The result of this evaluation shows that the independent innovation ability of the high-tech industry in Heilongjiang Province has gradually reduced, expanding the gap between the high-tech industry development of Heilongjiang and that of the national average. In recent years, the high-tech industry development of Heilongjiang has already fallen further behind the Eastern areas of China.
\end{abstract}

Keywords: mutation series; high-tech industry area of China; independent innovation ability

(Submitted on January 3, 2018; Revised on February 22, 2018; Accepted on March 23, 2018)

(C) 2018 Totem Publisher, Inc. All rights reserved.

\section{Introduction}

Attaining advanced and sophisticated technology has been the common goal of countries around the world. Thus, there is no doubt that the development the China's high-tech industry impacts China's position in international competition, which will enhance core national competitiveness and improve overall national strength. High-tech is at the forefront of sophisticated technology. With the development and creation of new technology, the more important feature is efficient evaluation and high-tech industry innovation ability. The high-tech industry is composed of industrial clusters that produce new high-tech product with contemporary cutting-edge technology (mainly including information technology, bioengineering and advanced material). Moreover, it is also an industry with high R\&D inputs and a high proportion of R\&D force [3]. China has high development in the high-tech area, but there is a significant difference among different areas [4].

This paper applies the mutation series method to evaluate the high-tech independent innovation ability of all the Chinese provinces, especially the undeveloped Heilongjiang Province for example. Through the analysis of Heilongjiang Province, the difference among different Chinese provinces will be pointed out in this paper, which will have some instructive significance to the high-tech industries of each area of China.

\section{The evaluation model construction based on the mutation series method}

The evaluation model construction consists of both the entropy model and mutation series model. While the entropy model is aimed at confirming the weight of index, the mutation series evaluates the demonstration according to the weight of index.

\subsection{The index weight calculation based on the entropy method}

The entropy method is used to get through the subjectivity of all kinds of index ranking, and it is also used to calculate each index weight. Moreover, it is also a relatively accurate objective weight method, by avoiding the subjective problems in the

\footnotetext{
* Corresponding author.

E-mail address: gongchen@hrbeu.edu.cn
} 
arrangement process of index weight and ensuring the agreement between the ranking and importance. The steps of weight determination by the promoting entropy method are as follows [5]:

To start, remove dimensions from the original data and standardize the index.

$$
x_{i j}^{\prime}=\frac{x_{i j}-x_{j}}{\sigma_{j}}
$$

In the above formula, $x_{i j}$ is the numerical value after dimensions are removed, and $x_{i j}$ is the original data of the $j$ index's $i$ evaluation. $x_{j}$ is the average value of the $j$ index, and $\sigma_{i j}$ is the standard deviation of the $j$ index. follows.

Next, in order to get rid of the influence of the minus after the dimensions are removed, it needs parallel translation as

$$
x_{i j}^{\prime \prime}=x_{i j}^{\prime}+D
$$

In formula (2), $x_{i j}^{\prime \prime}$ is the index value after the dimensions are removed, and $D$ is the parallel translation argument.

Then, calculate the weight $q_{i j}$ of each index according to $x_{i j}^{\prime \prime}$ :

$$
q_{i j}=\frac{x_{i j}^{\prime \prime}}{\sum_{i=1}^{m} x_{i j}^{\prime \prime}}
$$

Finally, calculate the mutation $e_{j}$ of the $j$ index according to $q_{i j}$ :

$$
q_{i j}=\frac{x_{i j}^{\prime \prime}}{\sum_{i=1}^{m} x_{i j}^{\prime \prime}}
$$

Thus, get $w_{i j}$, which is the $j$ index weight:

$$
w_{j}=\frac{1-e_{j}}{\sum_{j=1}^{n}\left(1-e_{j}\right)}
$$

For the evaluation index of the multilayered structure, add the utility value of the substratum structure together and get the corresponding weight of the super stratum index.

\subsection{The Mutation Series}

\subsubsection{The Conception}

To better master the theory of mutation, it is essential to grasp the basic conceptions of the mutation series method [12].

Potential function: the mutation theory is used to study the mutation phenomenon by the potential function of the research object. Potentiality is the ability of the system to adopt a certain trend, which depends on the relative relationships and interactions of the various components of the system. At the same time, the relative relationship between the system and the environment is also taken into account. The system potential function of the external control parameters can describe the behavior of the system through system state variables. (The system state variables represent the behavioral state of the system and factors that affect the behavioral state)

The potential function can be expressed as follows:

$$
V=V(x, c)
$$



$\left.c_{n}\right)$

In this formula, $V$ is the potential function, $x$ is the state variable $x=\left(x_{1}, x_{2}, \ldots, x_{n}\right), c$ is the control variable $c=\left(c_{1}, c_{2}, \ldots\right.$,

Critical point: Supposing $V=V(x, c)$ is a continuous smooth function, if at the point $u \in\left(x_{1}, x_{2}, \ldots, x_{n}\right)$, there is:

$$
\left.\frac{\partial V(x, c)}{\partial x_{1}}\right|_{u}=\cdots=\left.\frac{\partial V(x, c)}{\partial x_{n}}\right|_{u}=0
$$

In this formula, $u$ is called the critical point of the function $V$.

Profile of equilibrium: Profile of equilibrium is the hook face, which is made of all the critical points.

Set of singularities: The set of points that make the matrix Hessen $\Delta H(V)=\operatorname{det} H(V)=0$ of the potential function $V=V(x$, $c$ ) is called the set of singularities.

To get the solution set, which is called the bifurcation set, solve the simultaneous formulas $\Delta V(x)=0$ and $\operatorname{det} H(V)=0$, and eliminate all the state variables (univariate is $x$ ), namely a formula that is made of all of the controls parameter. Mapping makes the set of singularities (it can certainly be the whole profile of equilibrium) into the space of the controls parameter, whose trace is right of the bifurcation set. The mutation theory defines and controls the mutation phenomenon by analyzing the properties of the bifurcation set.

\subsubsection{Mutation series model}

Reduction of the mutation series model

The mutation series method based on the elementary mutation model and its bifurcation equation gets the normalized model by reduction. Then, use the normalized model to calculate the target system until it figures out the highest-level index value. There are normalized models originating from three common mutation models (cusp mutation, swallowtail catastrophe and butterfly catastrophe) [7]:

- The cusp catastrophe normalized model

It can be derived from the decomposed form of the cusp mutation bifurcation equation:

$$
x_{u}=\sqrt{\frac{u}{6}} \quad x_{v}=\sqrt[3]{\frac{v}{8}}
$$

In the formula, $x_{u}$ expresses the $x$ of $u$, and $x_{v}$ corresponds to the $x$ of $v$.

In order to simplify the operation, the value range of the state variable $x$ and control variable $u, v$ must be controlled between 0 and 1 .

When $x_{u}=1, u=6$, and if shrink $u 6$ times, the range will be between 0 and 1 , namely

$$
x_{u}=\sqrt{\frac{u}{6}}=\sqrt{u}
$$

In a similar way, shrink $v 8$ times makes the range between 0 and 1 ,

$$
x_{v}=\sqrt{\frac{v}{8}}=\sqrt[3]{v}
$$

Thus, the cusp catastrophe normalized model can be expressed: 


$$
x_{u}=\sqrt{u}, x_{v}=\sqrt[3]{v}
$$

- The Swallowtail catastrophe normalized model

$$
x_{u}=\sqrt{u}, x_{v}=\sqrt[3]{v}, x_{w}=\sqrt[4]{w}
$$

- The Butterfly catastrophe normalized model

$$
x_{u}=\sqrt{u}, x_{v}=\sqrt[3]{v}, x_{w}=\sqrt[4]{w}, x_{t}=\sqrt[5]{t}
$$

The value range of $x, u, v, w, t$ is between 0 and 1 .

\subsubsection{The comprehensive evaluation based on the normalized model}

According to the theory of multiple objective fuzzy decision, in the multiple situations, suppose $A_{l}, A_{2}, \ldots, A_{m}$ as fuzzy objects. Then, the ideal strategy is $C=A_{1} \cap A_{2} \cap \cdots \cap A_{m}$, its subordinate function is $u(x)=u_{A_{1}}(x) \cap u_{A_{2}}(x) \cap \cdots \cap$ $u_{A_{m}}(x)$, and $u_{A_{i}}(x)$ is the subordinate function of $A_{i}$. It is defined as the subordinate function of this scheme, that is to say it is the minimum value of all the objective subordinate functions [6].

Focusing on various schemes, suppose $G_{l}, G_{2}, \ldots, G_{n}$, and mark $u\left(G_{i}\right)$ as the subordinate function of $G_{i}$. Lying on the complementary and dimensionless principles, the total function value can be obtained. While the effect of each control value in the system cannot be mutually replaced, the control value is in a weak correlation. Then, the evaluation should be derived from the dimensionless theory, namely minimum. On the other hand, if each control value can complement each other, then the control value is in the strong correlation. Thus, it can be replaced by the average value and the evaluation should be achieved through the complementary theory, namely maximum. Besides, the evaluation objects should be ranked based on the scores of the total evaluation index. Only following the above principles, the requirement of the bifurcation set of the mutation series method can be catered

\section{Evaluation Index System and Data Acquisition}

\subsection{The construction of the evaluation index system}

There are so many factors that have a very complex influence on the independent innovation ability of the high-tech industry area of China. As a result, the evaluation index must be designed with multiple layers and perspectives so that it can reflect the operation effect completely and accurately. To ensure the evaluation index system is scientific, this paper gives out an evaluation index system of the independent innovation ability by the high-tech industry area of China according to the references of Yang [8], Wang [9], Shui [10], Liao [11], Bi [1,2].

Table 1. The evaluation index system of the high-tech industry area of independent innovation ability of China

\begin{tabular}{|c|c|c|}
\hline First grade indexes & Second grade indexes & Second grade code \\
\hline \multirow{4}{*}{ Input index A } & R\&D personnel FTE & A1 \\
\cline { 2 - 3 } & R\&D accounted for the proportion of the industry's total employment & A2 \\
\cline { 2 - 3 } & Industry R\&D funding input expenditure & A3 \\
\cline { 2 - 3 } & The proportion of government R\&D input in the total R\&D & A4 \\
\hline \multirow{3}{*}{ Output index B } & Industry-owned patents & B1 \\
\cline { 2 - 3 } & The number of patents & B2 \\
\cline { 2 - 3 } & Output of new products of industry & B3 \\
\hline
\end{tabular}

\subsection{Data information acquisition}

The evaluation research of the independent innovation ability by the high-tech industry area of China aims to obtain the overall situation. We want to construct a better, more scientific, more reasonable evaluation index system. Through the empirical analysis, we aim to examine the evaluation model and the results of the evaluation in order to outline the activity of the independent innovation ability of the high-tech industry of areas. 
The data of this paper is mainly from the China Statistical Yearbook (2005-2011), Yearbook of China intellectual property (2005-2011), Chinese high-tech industry Statistics Yearbook (2005-2011), as well as national statistical offices, the State Intellectual Property Office, Ministry of Science and Technology, and other portal sites. Through mathematical calculations, we obtained the index value from 29 provinces and cities in China.

\section{Evaluation of empirical analysis of independent innovation ability by high-tech industry areas of China}

\subsection{The establishment of the index weight}

Based on the improved entropy method, we calculated every index weight value of the evaluation index system, and using the national data as a weighted base as well as Formula (1), we calculated the standardized values of the indexes shown in the following Table 2:

Table 2. The standard index data

\begin{tabular}{|c|c|c|c|c|c|c|c|}
\hline & A1 & A2 & A3 & A4 & B1 & B2 & B3 \\
\hline 2005 & -1.131 & -0.424 & -1.068 & -1.030 & -0.928 & -1.104 & -1.207 \\
\hline 2006 & -1.004 & -0.430 & -0.816 & -1.200 & -0.874 & -0.855 & -0.911 \\
\hline 2007 & -0.526 & -0.393 & -0.577 & -0.559 & -0.684 & -0.513 & -0.469 \\
\hline 2008 & -0.230 & 2.265 & -0.282 & 0.592 & -0.303 & -0.337 & 0.007 \\
\hline 2009 & 0.610 & -0.332 & 0.355 & 0.496 & 0.324 & 0.731 & 0.145 \\
\hline 2010 & 0.689 & -0.382 & 0.558 & 0.095 & 0.650 & 0.338 & 0.715 \\
\hline 2011 & 1.592 & -0.303 & 1.829 & 1.607 & 1.814 & 1.740 & 1.721 \\
\hline
\end{tabular}

Through Formulas (2) and (3), the weight of each index is shown in Table 3:

Table 3. The proportion of all indexes in the annual

Table 3. The proportion of all indexes in the annual
\begin{tabular}{|c|c|c|c|c|c|c|c|}
\hline & A1 & A2 & A3 & A4 & B1 & B2 & B3 \\
\hline 2005 & 0.035 & 0.102 & 0.041 & 0.045 & 0.054 & 0.038 & 0.028 \\
\hline 2006 & 0.047 & 0.102 & 0.065 & 0.029 & 0.060 & 0.061 & 0.056 \\
\hline 2007 & 0.093 & 0.105 & 0.088 & 0.09 & 0.078 & 0.094 & 0.098 \\
\hline 2008 & 0.121 & 0.359 & 0.116 & 0.199 & 0.114 & 0.111 & 0.144 \\
\hline 2009 & 0.201 & 0.111 & 0.177 & 0.19 & 0.174 & 0.212 & 0.157 \\
\hline 2010 & 0.208 & 0.106 & 0.196 & 0.152 & 0.205 & 0.175 & 0.211 \\
\hline 2011 & 0.295 & 0.114 & 0.317 & 0.296 & 0.316 & 0.309 & 0.307 \\
\hline
\end{tabular}

After the standardization of the index values and proportions, Equations (4) and (5) calculated the weight of each index shown in the following Table 4:

Table 4. The indexes weight

\begin{tabular}{|c|c|c|}
\hline First grade indexes and weights & Second grade indexes & Second grade index weights \\
\hline \multirow{4}{*}{$\begin{array}{c}\text { Input index A } \\
0.49\end{array}$} & R\&D personnel FTE (A1) & 0.27 \\
\hline & R\&D accounted for the proportion of the industry's total employment (A2) & 0.20 \\
\hline & Industry R\&D funding input expenditure (A3) & 0.25 \\
\hline & The proportion of government R\&D input in the total R\&D (A4) & 0.28 \\
\hline \multirow{3}{*}{$\begin{array}{c}\text { Output index B } \\
0.51\end{array}$} & Industry-owned patents (B1) & 0.32 \\
\hline & The number of patents (B2) & 0.33 \\
\hline & Output of new products of industry (B3) & 0.35 \\
\hline
\end{tabular}

In Table 4 each of the index weights is ranked from big to small for the funding proportion of government R\&D, total R\&D, R\&D personnel FTE, Industry R\&D funding input expenditure, and R\&D accounted for the proportion of the industry's total employment.

\subsection{Empirical analysis and results}

Calculate the ranking of weights of each index. The control variables can be decided in the mutation series based on the evaluation of the regional independent innovation ability by the high-tech industries in China. We evaluated the independent innovation ability by high-tech industries in 29 provinces in China in 2011 as an example. In order to avoid the difference raised from the different dimensional units between the evaluation indexes and statistics, according to the requirements of the mutation theory, it is necessary to transform the raw data of the control variable into the interval value [0,1] using Formula (9) on the standardized index data:

$$
y_{i j}=\frac{x_{i j}-\min _{1 \leq j \leq n}}{\max _{1 \leq j \leq n} x_{i j}-\min _{1 \leq j \leq n} x_{i j}}, i=1,2, \cdots, m ; j=1,2, \cdots, n
$$


Above, $i$ shows the index number and $j$ shows the number of objects. According to Formula (9), the standardization of the 2011 data results are shown in Table 5:

\begin{tabular}{|c|c|c|c|c|c|c|c|}
\hline & A1 & A2 & $\mathrm{A} 3$ & A4 & B1 & B2 & B3 \\
\hline Beijing & 0.0994 & 0.8183 & 0.1530 & 1 & 0.0907 & 0.1576 & 0.2068 \\
\hline Tianjin & 0.0573 & 0.4653 & 0.0654 & 0.4912 & 0.0389 & 0.0696 & 0.0989 \\
\hline Hebei & 0.0356 & 0.3746 & 0.0231 & 0.1092 & 0.0104 & 0.0125 & 0.0103 \\
\hline Shanxi & 0.0077 & 0.0554 & 0.0041 & 0.1444 & 0.0029 & 0.0052 & 0.0034 \\
\hline Neimenggu & 0 & 0 & 0 & 0 & 0.0003 & 0.0007 & 0.0003 \\
\hline Liaoning & 0.0380 & 0.4310 & 0.1186 & 0.3047 & 0.0209 & 0.0337 & 0.0457 \\
\hline Jilin & 0.0182 & 0.2767 & 0.0117 & 0.0851 & 0.0055 & 0.0083 & 0.0092 \\
\hline Heilongjiang & 0.0339 & 0.9602 & 0.0345 & 0.2155 & 0.0106 & 0.0143 & 0.0064 \\
\hline Shanghai & 0.1050 & 0.3002 & 0.1478 & 0.2242 & 0.0793 & 0.1273 & 0.1351 \\
\hline Jiangsu & 0.4440 & 0.3017 & 0.4373 & 0.3110 & 0.1513 & 0.3881 & 0.4911 \\
\hline Zhejiang & 0.2318 & 0.7617 & 0.1796 & 0.5883 & 0.1031 & 0.1835 & 0.1625 \\
\hline Anhui & 0.0454 & 0.8966 & 0.0419 & 0.4864 & 0.0148 & 0.0575 & 0.0404 \\
\hline Fujian & 0.1254 & 0.6842 & 0.1084 & 0.6797 & 0.0252 & 0.0606 & 0.1527 \\
\hline Jiangxi & 0.0417 & 0.2726 & 0.0327 & 0.1545 & 0.0089 & 0.0136 & 0.0198 \\
\hline Shandong & 0.1620 & 0.5897 & 0.2046 & 0.3982 & 0.0522 & 0.1420 & 0.1920 \\
\hline Henan & 0.0534 & 0.1987 & 0.0269 & 0.0713 & 0.0127 & 0.0402 & 0.0183 \\
\hline Hubei & 0.0998 & 0.9435 & 0.0974 & 0.3323 & 0.0437 & 0.0451 & 0.0449 \\
\hline Hunan & 0.0323 & 0.3377 & 0.0409 & 0.3371 & 0.0178 & 0.052 & 0.0407 \\
\hline Guangdong & 1 & 0.4594 & 1 & 0.5661 & 1 & 1 & 1 \\
\hline Guangxi & 0.0113 & 0.2273 & 0.0120 & 0.0948 & 0.0049 & 0.006 & 0.0055 \\
\hline Hainan & 0.0020 & 0.6299 & 0.0017 & 0.0995 & 0.0017 & 0.0047 & 0 \\
\hline Chongqing & 0.0235 & 0.4093 & 0.0134 & 0.6204 & 0.0076 & 0.0237 & 0.0524 \\
\hline Sichuan & 0.0349 & 0.3146 & 0.0756 & 0.3398 & 0.0651 & 0.0493 & 0.0865 \\
\hline Guizhou & 0.0216 & 0.7034 & 0.0157 & 0.3493 & 0.009 & 0.0155 & 0.0092 \\
\hline Yunnan & 0.0093 & 1 & 0.0073 & 0.4072 & 0.0065 & 0.0062 & 0.0053 \\
\hline Shanxi & 0.0747 & 0.7513 & 0.0962 & 0.3318 & 0.0242 & 0.0327 & 0.0272 \\
\hline Gansu & 0.0033 & 0.4464 & 0.0034 & 0.3707 & 0.0009 & 0.0028 & 0.0017 \\
\hline Ningxia & 0.0010 & 0.9937 & 0.0003 & 0.8151 & 0 & 0.0022 & 0.0016 \\
\hline Xinjiang & 0.0012 & 0.5855 & 0.0019 & 0.5423 & 0.0001 & 0 & 0.0003 \\
\hline
\end{tabular}

Using the 2011 data of Heilongjiang province as an example, calculate the independent innovation ability of the hightech industry in Heilongjiang Province in 2011 by the mutation series:

The indexes donating the input in the third indexes consist of four indexes, namely A1, A2, A3 and A4, which form the butterfly catastrophe system model by computing the correlation coefficient obtained. They show the weak relationship between the variables. Because the index role cannot be replaced according to the "non-complementary principle", the calculated control variables should be sorted according to their sizes as follows:

$$
\begin{gathered}
X_{A 4}=\sqrt{A 4}=\sqrt{0.215527}=0.464249 \\
X_{A 1}=\sqrt[3]{A 1}=\sqrt[3]{0.033924}=0.323718 \\
X_{A 3}=\sqrt[4]{A 3}=\sqrt[4]{0.034469}=0.430881 \\
X_{A 2}=\sqrt[5]{A 2}=\sqrt[5]{0.9602427}=0.991919 \\
X_{A}=\min \left(X_{A 1}, X_{A 2}, X_{A 3}, X_{A 4}\right)=0.323718
\end{gathered}
$$

The indexes donating the output in the third grade consist of three indexes, known as B1, B2 and B3, which form the Swallowtail catastrophe mutation model. By computing the correlation confident, which shows strong correlations between variables, each index can replace each other according to the "complementary principle" or the "small fetch big" value principle. The weight of each control variable is sorted by size. The calculated control variable should be sorted according to its size as follows: 


$$
\begin{gathered}
X_{B 3}=\sqrt{B 3}=\sqrt{0.006359}=0.079742 \\
X_{B 2}=\sqrt[3]{B 2}=\sqrt[3]{0.014347}=0.242992 \\
X_{B 1}=\sqrt[4]{B 1}=\sqrt[4]{0.010564}=0.320592 \\
X_{B}=\operatorname{average}\left(X_{B 1}, X_{B 2}, X_{B 3}\right)=0.214442
\end{gathered}
$$

In the second index, A and B form the cusp catastrophe model by computing the correlation coefficient, which shows strong correlations between variables. Each index can replace each other according to the "complementary principle" or the "small fetch big" value principle. Each control variable weight is B and A. The controlled variable calculated should be sorted according to its size. The final value of the independent innovation ability by the high-tech industry in Heilongjiang in 2011 is:

\begin{tabular}{|c|c|c|c|c|c|c|c|}
\hline & 2011 & 2010 & 2009 & 2008 & 2007 & 2006 & 2005 \\
\hline Beijing & 0.746 & 0.709 & 0.766 & 0.7653 & 0.8 & 0.743 & 0.773 \\
\hline Tianjin & 0.676 & 0.667 & 0.697 & 0.7022 & 0.702 & 0.711 & 0.727 \\
\hline Hebei & 0.578 & 0.581 & 0.609 & 0.5727 & 0.583 & 0.613 & 0.614 \\
\hline Shanxi & 0.488 & 0.479 & 0.523 & 0.4522 & 0.217 & 0.487 & 0.473 \\
\hline Neimenggu & 0.141 & 0.049 & 0.102 & 0.0246 & 0.303 & 0.384 & 0.183 \\
\hline Liaoning & 0.624 & 0.588 & 0.647 & 0.6374 & 0.661 & 0.676 & 0.696 \\
\hline Jilin & 0.538 & 0.496 & 0.57 & 0.521 & 0.533 & 0.556 & 0.54 \\
\hline Heilongjiang & 0.575 & 0.556 & 0.585 & 0.5749 & 0.591 & 0.612 & 0.65 \\
\hline Shanghai & 0.731 & 0.744 & 0.784 & 0.7525 & 0.782 & 0.817 & 0.805 \\
\hline Jiangsu & 0.825 & 0.795 & 0.824 & 0.8176 & 0.81 & 0.753 & 0.748 \\
\hline Zhejiang & 0.783 & 0.744 & 0.799 & 0.7585 & 0.768 & 0.783 & 0.767 \\
\hline Anhui & 0.634 & 0.602 & 0.612 & 0.5767 & 0.566 & 0.551 & 0.56 \\
\hline Fujian & 0.711 & 0.694 & 0.714 & 0.6953 & 0.719 & 0.727 & 0.746 \\
\hline Jiangxi & 0.59 & 0.577 & 0.603 & 0.5706 & 0.614 & 0.624 & 0.633 \\
\hline Shandong & 0.755 & 0.721 & 0.758 & 0.7416 & 0.749 & 0.747 & 0.748 \\
\hline Henan & 0.582 & 0.61 & 0.651 & 0.6109 & 0.621 & 0.625 & 0.62 \\
\hline Hubei & 0.679 & 0.656 & 0.686 & 0.64 & 0.659 & 0.674 & 0.59 \\
\hline Hunan & 0.621 & 0.6 & 0.624 & 0.576 & 0.559 & 0.572 & 0.598 \\
\hline Guangdong & 0.955 & 0.947 & 0.925 & 0.9118 & 0.907 & 0.919 & 0.917 \\
\hline Guangxi & 0.512 & 0.485 & 0.511 & 0.4897 & 0.522 & 0.521 & 0.541 \\
\hline Hainan & 0.426 & 0.153 & 0.45 & 0.3156 & 0.086 & 0.07 & 0.054 \\
\hline Chongqing & 0.59 & 0.578 & 0.601 & 0.5846 & 0.59 & 0.606 & 0.597 \\
\hline Sichuan & 0.656 & 0.613 & 0.702 & 0.7087 & 0.731 & 0.722 & 0.71 \\
\hline Guizhou & 0.56 & 0.582 & 0.577 & 0.5705 & 0.589 & 0.615 & 0.607 \\
\hline Yunnan & 0.51 & 0.487 & 0.505 & 0.4971 & 0.512 & 0.509 & 0.521 \\
\hline Shanxi & 0.645 & 0.635 & 0.66 & 0.6551 & 0.694 & 0.7 & 0.713 \\
\hline Gansu & 0.438 & 0.445 & 0.439 & 0.4695 & 0.436 & 0.477 & 0.496 \\
\hline Ningxia & 0.35 & 0.382 & 0.407 & 0.4653 & 0.427 & 0.462 & 0.492 \\
\hline Xinjiang & 0.339 & 0.107 & 0.156 & 0.1392 & 0.154 & 0.16 & 0.17 \\
\hline
\end{tabular}

$$
\begin{gathered}
X_{B}=\sqrt{B}=\sqrt{0.214442}=0.463079 \\
X_{A}=\sqrt[3]{A}=\sqrt[3]{0.3237184}=0.686629 \\
r=\operatorname{average}\left(X_{A}, X_{B}\right)=0.574854
\end{gathered}
$$

Similarly, applying the above calculation steps, we can get all evaluations of the independent innovation abilities by high-tech industries of all the provinces from 2005-2011, as shown in Table 6 below:

The above Table 6 has shown the evaluation value of the independent innovation abilities of high-tech industries of the main 29 provinces in China. The results of the evaluation of Heilongjiang from 2005-2011 are respectively: 0.650, 0.612, 0.591 and $0.575,0.585,0.556,0.575$. There is a time series trend chart as follows: 


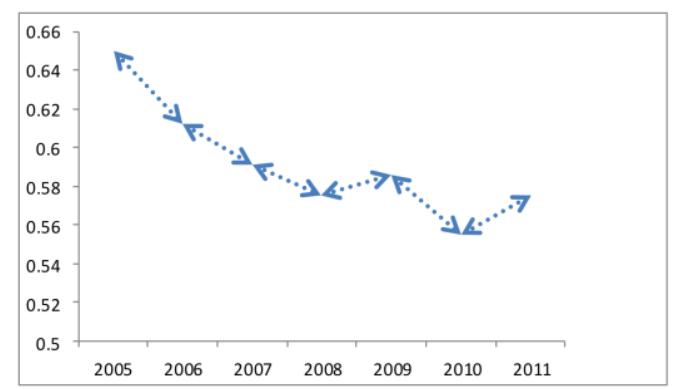

Figure 1. The development trend of independent innovation ability of Heilongjiang province in recent years

From this figure, it can be seen that the independent innovation ability of Heilongjiang province from 2005-2011 declined, especially from 2005-2008. Although 2008-2009 appeared to rise, this trend was not maintained, as 2009-2010 declined again. One of the main reasons is that with the development of the continued in-depth China reform, the independent innovation ability Heilongjiang province, as an old inland area industrial base, continued to atrophy. Heilongjiang province, which mainly manufactures traditional equipment, is impacted by the central-southern region of Liaoning as well as the BTT region, which are well-developed industrial areas. On the other hand, Heilongjiang province was also influenced by the global economic crisis of 2008, which not only affected its independent innovation ability, but also its patents. These reasons lead to the decline in the ability to independently innovate by the high-tech industry of Heilongjiang.

In order to better look at the ability of independent innovation by the high-tech industry of Heilongjiang province, we need to compare it with the average level in other areas of China in recent years:

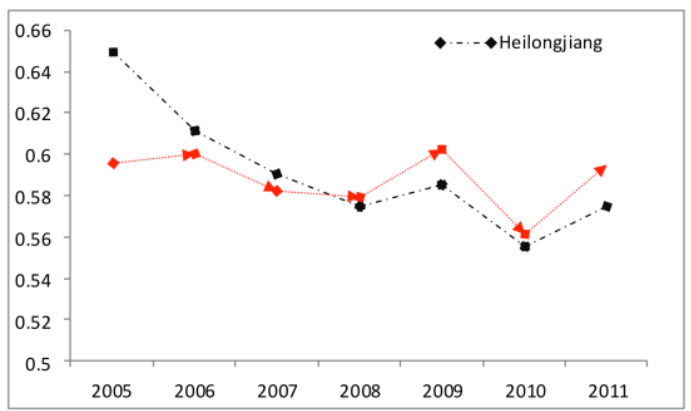

Figure 2. The area chart between Heilongjiang province and the average level of China

From this chart, we can see that before 2008, the ability of independent innovation by the high-tech industry of Heilongjiang province is higher than the average level of the whole nation. For instance, the evaluation value of Heilongjiang province in 2005 is 0.65 , while the average level of the whole nation is less than 0.5 . However, as time goes by, this difference gets smaller and smaller. After 2008, the evaluation value of the whole nation completely supersedes that of Heilongjiang. Therefore, it can be seen that the ability of independent innovation by the high-tech industry of Heilongjiang province has weakened. What's worse, the gap is getting bigger and bigger.

In addition, we look at the development of three provinces of Northeast China through factors such as location, scale of population, historical development and so on:

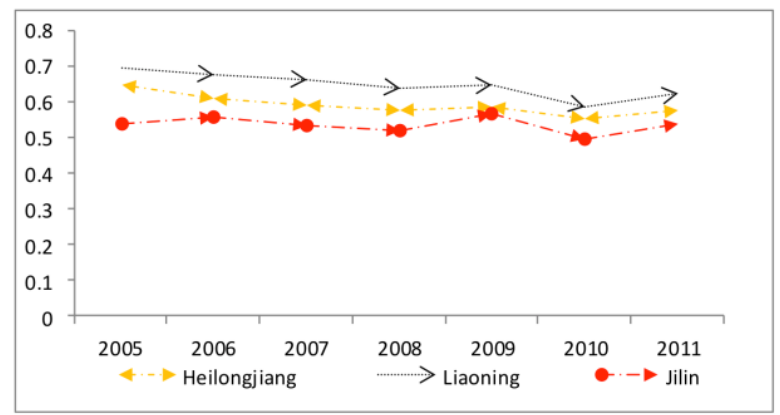

Figure 3. The area chart of the tee provinces in the northeast of China 
The figure shows the development trend of the ability of independent innovation by the high-tech industries of the three provinces in Northeast China from 2005-2011. From the figure, it can be seen that the trend of the ability of independent innovation by the high-tech industries of the three provinces in the Northeast China declines before 2010. Then, after 2010, it begins to rise quickly. The two trends appear in the Heilongjiang and Liaoning provinces, and the fluctuation is relatively big in the Jilin and Liaoning provinces. Compared to the evaluation value of the whole nation in recent years, Liaoning leads in the area of the ability of independent innovation by high-tech industry. Following is Heilongjiang, and finally Jilin, which corresponds to the actual development of the three provinces.

In addition, we further compare the ability of independent innovation by the high-tech industry between Heilongjiang province and the developed eastern provinces. The gap between Heilongjiang province and the developed provinces is obvious:

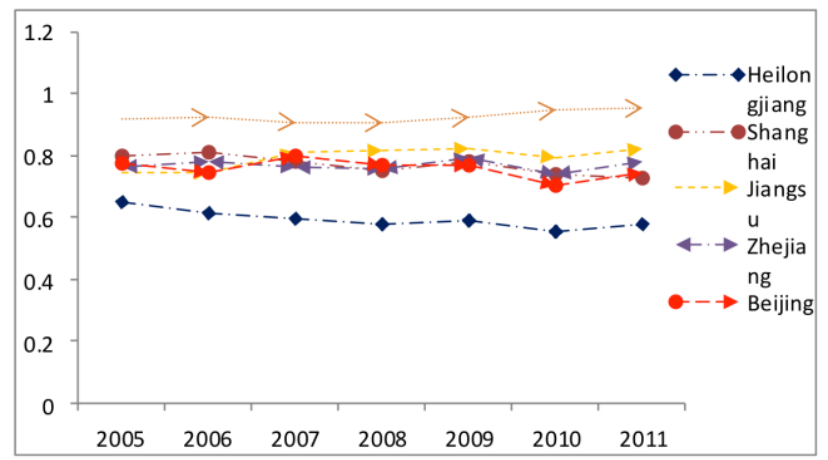

Figure 4. The area chart between Heilongjiang province and the developed eastern provinces

From this figure, it can be seen that the development of high-tech industries of Heilongjiang province lags far behind Shanghai, Jiangsu, Zhejiang, Beijing, Guangdong and so on. From the recent trend, the ability of independent innovation by the high-tech industry of Heilongjiang province is declining, while the developed eastern provinces are rising and even maintaining a higher development level. In the above eastern provinces, the Guangdong high-tech industry has the highest ability of independent innovation. Therefore, Heilongjiang province needs to learn a lot from Guangdong province in order to promote the development of the high-tech industry of Heilongjiang province.

\section{Conclusions}

This paper constructs an evaluation model on independent innovation of high-tech industry areas of China based on the entropy evaluation method and the mutation series method. The index system lies in the research input and the patent output, and it also provides the empirical evaluation of the ability of independent innovation by high-tech industries of 29 provinces in China from 2005-2011. The longitudinal comparison of the development trend of Heilongjiang province showed that its ability of independent innovation by its high-tech industry is declining, while other provinces in China as well as the average level are increasing, leading to a bigger and bigger gap. Furthermore, the development of the Heilongjiang province has fallen far behind eastern provinces in recent years. According to the final ranking result of the mutation series, the presentation of the ability of independent innovation by high-tech industries of the whole nation from $2005-2011$ is not consistent, and the ability of independent innovation by high-tech industries of all the provinces in China is unbalanced year after year.

Compared with manual diagnosis, the automated method is not only convenient and saves time, but also reduces the labor intensity of doctors. The present study focuses on the feature selection and classification methods. The features are ranked according to weight using ReliefF. RF has been applied to classify cervical cells with different dimensional features. The experimental results showed the effectiveness of the proposed method and compared it with the results based on NB, C4.5, and LR. The effectiveness of different types of features was also analyzed, suggesting that automated analysis should include cytoplasm features.

\section{References}

1. K. X. Bi, P. Huang, and X. Wang, "Innovation Performance and Influencing Factors of Low-Carbon Technological Innovation Under the Global Value Chain: A Case of Chinese Manufacturing Industry," Technological Forecasting \& Social Change, vol.101, no. 111, pp. 275-284, 2016

2. K. X. Bi, P. Huang, and H. Ye, "Risk Identification, Evaluation and Response of Low-Carbon Technological Innovation under 
the Global Value Chain: A Case of the Chinese Manufacturing Industry," Technological Forecasting \& Social Change, vol. 100, no. 4, pp. 238-248, 2015

3. W. Chen, Z. L. Yang, W. Zhou, Y. Long, "Knowledge-Intensive Manufacturing Technology Innovation Capability Based on Catastrophe Progression-The Changing Perspective of the Characteristics of Dynamic Comprehensive Evaluation," Operations Research and Management Science, no. 1, pp. 191-201, 2015

4. W. Chen, Z. L. Yang, and Y. C. Zhang, "Empirical Study on the Relationship Between Network Structure and Enterprises Core Ability: Based on the Perspective of Knowledge-Sharing and Knowledge Integration Mediators," Management Review, no. 6, pp. 74-82, 2014

5. X. G. Guo, "Improved Entropy Method and Its Application in Economic Evaluation," Systems Engineering Theory and Practice, no. 12 , pp. 98-102, 1998

6. J. L. Jie, S. H. Hu, and Y. Y. Jiang, "Based on Catastrophe Progression Method in Study on Spatial Variation of Competitiveness of National High-Tech Zone," Science of Science and Management of Science and Technology, vol. 32, no. 12, pp. 101-107, 2011

7. Y. Li, X. H. Chen, and P. F. Zhang, "Application of Catastrophe Progression Method in Regional Ecosystem Health Assessment," Population Resources and Environment in China, no. 3, pp. 50-54, 2007

8. L. H. Liao, X. D. Li, "Based on Combination of Factor Analysis and TOPSIS Evaluation of Building Industry a Competitive Edge in China," Engineering Management Journal, no. 5, pp. 7-11, 2012

9. W. Shui, "Indicator System of Regional Manufacturing Industrial Competitiveness Evaluation Model, Construction and Application-Based on Visual Angle of Comparative Advantage and Competitive Advantage of Dynamic Equilibrium," Industrial Technology Economics, vol. 28, no. 3, pp. 68-72, 2009

10. D. Z. Wang, D. W. Zhao, and J. M. Chen, "Model of Industrial Competitive Advantage: An Empirical Study on Green Food Industry in Heilongjiang Province," China Industrial Economics, no. 5, pp. 32-39, 2006

11. G. C. Yang, T. Liu, and G. Li, "Multiple Perspective Study on the Comprehensive Evaluation Model of Enterprise's Technological Competitive Advantage," Information Journal, vol. 32, no. 3, pp. 251-261, 2013

12. S. Q. Zhu, "Performance Evaluation of Listed Companies Based on Catastrophe Progression Method," Systems Engineering Theory and Practice, no. 2, pp. 90-94, 2002 